\title{
EVALUATION OF THE EFFICACY OF A HYDROGEN PEROXIDE DISINFECTANT
}

\author{
LUZ KARIME MEDINA-CORDOBA ${ }^{1}$, LIGIA LUCIA VALENCIA-MOSQUERA², GRETTY PAOLA TARAZONA-DIAZ ${ }^{3}$, \\ JANETH DEL CARMEN ARIAS-PALACIOS ${ }^{*}$
}

${ }^{1}$ Industrial Microbiologist, M. Sc. Georgia Institute of Technology, Atlanta, Georgia, ${ }^{2}$ Industrial Microbiologist Head of Quality Control in

Documentary Management EOS, Bogotá, Colombia, ${ }^{3}$ Bacteriólogist, Administrative and Marketing Manager at REQPERA I. P. S., S. A. S., ${ }^{4}$ Bacteriólogist, M. Sc. Environmental and Industrial Biotechnology Group, Department of Microbiology Pontificia Universidad Javeriana, Bogota, Colombia

Email: jdcarias@javeriana.edu.co

Received: 06 Jan 2018 Revised and Accepted: 07 Sep 2018

\section{ABSTRACT}

Objective: To evaluate the efficacy of a disinfectant based on hydrogen peroxide.

Methods: The method used to assess the efficacy of the disinfectant was the agar plate technique. With this procedure, it was possible to determine the percentage of inhibition of the high-level disinfectant of STERIS against four microorganisms, i.e., Pseudomonas aeruginosa ATCC 9027 Staphylococcus aureus (Beta-Hemolytic 227), Salmonella choleraesuis (Kuznedorf CMDM 074), and Bacillus subtilis (ATCC 6633). The effectiveness of five disinfectant concentrations $(0.02 \%, 0.04 \%, 0.08 \%, 1 \%$, and $2 \%)$ was determined and evaluated in three different times 5,10 , and 15 min, for vegetative strains and 3,6 , and $9 \mathrm{~h}$ for the sporulated strain.

Results: According to the experimental test, the reduction of the microbial population was, on average, $100 \%$ for the disinfectant concentrations of $0.08 \%, 1 \%$, and $2 \%$.

Conclusion: The results obtained demonstrated that the high-level disinfectant of STERIS based on hydrogen peroxide is $100 \%$ effective when the concentration recommended by the commercial house $(2 \%)$ is used in the shortest time exposure to disinfectant. The minimum level of effectiveness was $0.08 \%$; however, if lower concentrations are used, destruction of the microorganisms is not guaranteed.

Keywords: Bactericidal activity, Effectiveness, Antiseptic, The percentage inhibition

(C) 2018 The Authors. Published by Innovare Academic Sciences Pvt Ltd. This is an open access article under the CC BY license (http://creativecommons.org/licenses/by/4.0/) DOI: http://dx.doi.org/10.22159/ijpps.2018v10i10.24652

\section{INTRODUCTION}

In all fields of research, in which chemical products must be used, a disinfectant is required to reliably prevent microbial contamination and keep surfaces and work equipment clean at the same time. Cleaning and disinfection, together with sterilization, constitute the primary and most effective elements to break the epidemiological chain of infection. Hospital infections are a topic of relevant interest due to their frequency, severity, and economic repercussions.

The disinfection of instruments and surfaces of workstations, precisely in the laboratory where scientists analyze numerous biological samples, require the use of disinfectants to avoid possible contamination [1].

Hospital-acquired infection (HAI) is one of the critical concerns because it takes a heavy toll on patients and their families, as it causes illness, prolongs hospital stays, reduces the quality of life, increases the potential of disabilities, and increases the resistance of the microbes to antimicrobials as well as leading to excess costs and sometimes death of the patient. Education and training of healthcare workers about standard infection control and strict adherence by healthcare staff to aseptic practice can reduce the extent of risks of HAI. Rational use of disinfectants leads to a substantial reduction in HAI and requirement of disinfectants [2].

Hospital care poses the highest hygiene requirements because medical devices and surgical instruments, such as implants, have direct contact with body fluids. Poor hygiene of these instruments can cause irreversible infections in immunosuppressed patients or death. For this reason, it is necessary to use a disinfectant that is effective not only in eliminating the microorganisms quickly and reliably but also avoiding harm to the patient's health and eliminating unpleasant odors [3]. For the development of this research, the high-level disinfectant of STERIS, with a hydrogen peroxide base, was evaluated in in vitro tests that guarantee its use in instruments and medical devices in the hospital sector.

\section{MATERIALS AND METHODS}

\section{Study population}

High-level disinfectant of STERIS, based on hydrogen peroxide, was used in the disinfection of equipment and devices for hospital purposes.

\section{Study design}

This research is descriptive analytic research with quantitative methods.

\section{Sampling}

The study was carried out facing strains of the following microorganisms (Pseudomonas aeruginosa, Staphylococcus aureus, Salmonella choleraesuis, Bacillus subtilis) at different disinfectant concentrations. The strains were provided by the Pontificia Universidad Javeriana, Bogotá, Colombia. Different concentrations of the disinfectant were evaluated against diverse microbial strains. Two repetitions were made for each microorganism with the three levels of the disinfectant. The contact times of the disinfectant versus microorganism was 5,10 , and 15 min for vegetative bacteria and a period of 3,6 , and $9 \mathrm{~h}$ for the sporulated strain. Using different times helped us to determine if the recommended time established by the disinfectant house production is appropriate or if it is necessary to increase the exposure time when applying the disinfectant on equipment [4].

\section{Study variables}

Dependent variables

Percentage of microbial inhibition of each concentration of the evaluated disinfectant will be calculated using the average inhibition of the replicas of each microorganism assessed. 


\section{Independent variables}

The different concentrations at which the disinfectant agent was evaluated (recommended level, half, and double). 2. The different exposure times for the three bacterial strains $5 \mathrm{~min}, 10 \mathrm{~min}$, and 15 min; 3, 6 and $9 \mathrm{~h}$ for the sporulated strain.

\section{Controls}

To evaluate disinfectants, methods such as phenolic coefficient, plate count, tube dilution, and determination of the minimum inhibitory concentration (mic), among others are used. This work used as a positive control (mic) a $90 \%$ alcohol suspension to confront the microorganisms at the same times to verify the inhibition. As a negative control, this work used a suspension of $0.85 \%$ saline solution to confront the microorganisms at the same time to verify the growth.

\section{Statistical model}

The data obtained during the investigation were statistically analyzed by the Mann-Whitney, and Kruskal-Wallys test with a confidence level of $75 \%$. In this way, the effectiveness of the different concentrations of the disinfectant was determined, compared with the microorganisms mentioned in the technical sheet.

\section{Microorganisms}

The microorganisms evaluated were Bacillus subtilis ATCC 6633, Pseudomonas aeruginosa ATCC 9027, Staphylococcus aureus betahemolytic, and Salmonella choleraesuis, which were preserved in Petri dishes at $5{ }^{\circ} \mathrm{C}$ and made a microscopic identification using the Gram stain. The microorganisms were provided from the Pontificia Universidad Javeriana Bogotá, Colombia.

\section{Disinfectant}

It was supplied by STERIS, the manufacturer, and prepared according to its recommendations.

\section{Culture media}

Brain heart infusion (BHI) broth was used to inoculate the microorganism and reproduce it; BHI agar was used as a culture medium for sowing and recovery of Salmonella choleraesuis, Staphylococcus aureus, Bacillus subtilis, and Pseudomonas aeruginosa.

\section{Inoculation preparation}

(preparation of microorganisms for testing): The bacterial suspension was standardized following the CLSI guidelines and was grown in BHI broth, for 18-24 h; the suspensions of the microorganisms were prepared in saline solution at $0.85 \%(\mathrm{w} / \mathrm{v})$ in a tube of $13 \times 100 \mathrm{~mm}$, whose final concentration should be 6 $\mathrm{x} 10^{8}$ cells $/ \mathrm{ml}$. In a $16 \times 150 \mathrm{~mm}$ tube with BHI broth, the suspension of microorganisms prepared in saline solution was inoculated. The inoculum was incubated at $37{ }^{\circ} \mathrm{C}$ for $24 \mathrm{~h}$. At the end of the incubation time, the purity of the strains was verified using Gram staining, and a count was carried out to determine the exact value of each of the numbers, ensuring that they were at $10^{8}$. In the case of Bacillus subtillis, it was incubated at a temperature of $37^{\circ} \mathrm{C}$ for $72 \mathrm{~h}$. From this inoculum, the tests for the evaluation of the disinfectant were carried out [5].

\section{Preparation of disinfectant concentrations}

Disinfectant concentrations were prepared at $0.02 \%, 0.04 \%, 0.08 \%$, $1 \%$, and $2 \%$ to perform in vitro tests for the effectiveness against the bacterial strains.

\section{Disinfectant evaluation}

Efficacy of the disinfectant was evaluated at different concentrations and different times against the established microorganisms, according to [6].

Five levels of the disinfectant were previously prepared at the recommended dosage by the commercial house, at the half of the recommended dose and twice the recommended dose.

$2 \mathrm{ml}$ of each disinfectant concentration was evaluated in test tubes.

$0.2 \mathrm{ml}$ of the suspensions with the established microorganisms were inoculated into each tubes with the disinfectant concentrations.

Tubes were then shaken for 5,10 , and $15 \mathrm{~min}$.

Subsequently, the suspension with the disinfectant and the microorganisms were dispensed in Petri plates with BHI agar for 48 $h$, and a plate count was carried out to verify the inhibition percentages from the initial count $[6,7]$.

\section{Reading and interpretation}

After the incubation time, the samples were read, and the plate count was made.

\section{Control}

For the negative control, we expected to have grown around $10^{8} \mathrm{CFU}$ and the positive control boxes should show growth inhibition of $100 \%[6,8]$.

The results obtained through this experimental test were examined using a descriptive analysis through tables and graphs, where the growth of each microorganism is observed after being exposed to each of the concentrations and evaluation time of the disinfectant. In this way, the best disinfectant concentration that inhibits the growth of each microorganism was established.

For this purpose, the following hypotheses were tested

\section{Null hypothesis (Ho)}

The percentage of inhibition of the evaluated concentrations $(0.02 \%$, $0.04 \%, 0.08 \%, 1 \%$, and $2 \%$ ) of the disinfectant is $\geq$ than $75 \%$.

\section{Alternate hypothesis (Hi)}

The percentage of inhibition of the concentrations evaluated $(0.02 \%$, $0.04 \%, 0.08 \%, 1 \%$, and $2 \%$ ) of the disinfectant is $<75 \%$.

\section{Decision}

For all probability values equal to or less than 0.05 , the alternative hypothesis is accepted; therefore, the null hypothesis is rejected. Conclusively, the percentage of inhibition is not the same in the three evaluated concentrations of the disinfectant, at least one is different.

\section{RESULTS}

\section{Inhibition percentage}

Table 1: Percentage of inhibition of each microorganism against different concentration of the disinfectant

\begin{tabular}{|c|c|c|c|c|c|c|c|c|c|c|c|c|}
\hline \multirow[t]{2}{*}{ Concentration } & \multicolumn{3}{|c|}{ Staphilococcus aureus } & \multicolumn{3}{|c|}{ Pseudomonas aeruginosa } & \multicolumn{3}{|c|}{ Salmonella chlorerasuis } & \multicolumn{3}{|c|}{ Bacillus subtillis } \\
\hline & 5 Min & $10 \mathrm{Min}$ & 15 Min & 5 Min & $10 \mathrm{Min}$ & 15 Min & 5 Min & $10 \mathrm{Min}$ & 15 Min & $3 \mathrm{~h}$ & $6 \mathrm{~h}$ & $9 \mathrm{~h}$ \\
\hline $0.02 \%$ & 0 & 0 & 25 & 0 & 0 & 28.12 & 0 & 0 & 42.15 & 50 & 50 & 87.25 \\
\hline $0.04 \%$ & 0 & 43.75 & 100 & 87.5 & 100 & 100 & 0 & 62.5 & 100 & 68.75 & 96 & 100 \\
\hline $0.08 \%$ & 100 & 100 & 100 & 100 & 100 & 100 & 100 & 100 & 100 & 100 & 100 & 100 \\
\hline $1 \%$ & 100 & 100 & 100 & 100 & 100 & 100 & 100 & 100 & 100 & 100 & 100 & 100 \\
\hline $2 \%$ & 100 & 100 & 100 & 100 & 100 & 100 & 100 & 100 & 100 & 100 & 100 & 100 \\
\hline
\end{tabular}

Data from table 1 correspond to the average of the replicates and show the inhibition rates over time of the strains used against the different concentrations of disinfectant 
Table 2: Comparison of the behavior of the strains in connection with the concentrations of the disinfectant

\begin{tabular}{|c|c|c|c|c|c|c|c|c|c|c|c|c|c|c|c|}
\hline \multirow{2}{*}{$\begin{array}{l}\text { Microorganism } \\
\text { Exposition time in minutes }\end{array}$} & \multicolumn{3}{|c|}{ Inhibition $0.02 \%$} & \multicolumn{3}{|c|}{ Inhibition $0.04 \%$} & \multicolumn{3}{|c|}{ Inhibition $0.08 \%$} & \multicolumn{3}{|c|}{ Inhibition 1\% } & \multicolumn{3}{|c|}{ Inhibition $2 \%$} \\
\hline & 5 & 10 & 15 & 5 & 10 & 15 & 5 & 10 & 15 & 5 & 10 & 15 & 5 & 10 & 15 \\
\hline Staphilococcus aureus & 0 & 0 & 25 & 0 & 44 & 100 & 100 & 100 & 100 & 100 & 100 & 100 & 100 & 100 & 100 \\
\hline Pseudomonas aeruginosa & 0 & 0 & 28 & 88 & 100 & 100 & 100 & 100 & 100 & 100 & 100 & 100 & 100 & 100 & 100 \\
\hline Salmonella chlorerasuis & 0 & 0 & 42 & 0 & 63 & 100 & 100 & 100 & 100 & 100 & 100 & 100 & 100 & 100 & 100 \\
\hline Exposition time in minutes & 3 & 6 & 9 & 3 & 6 & 9 & 3 & 6 & 9 & 3 & 6 & 9 & 3 & 6 & 9 \\
\hline Bacillus subtillis & 50 & 50 & 100 & 69 & 96 & 100 & 100 & 100 & 100 & 100 & 100 & 100 & 100 & 100 & 100 \\
\hline
\end{tabular}

Comparison of the percentages of inhibition of the different strains concerning the concentrations of disinfectant can be observed in table 2

\section{Evaluation of the efficacy of the disinfectant against micro- organisms}

The table 1, show the effectiveness of the high-level hydrogen peroxide-based disinfectant of STERIS in the presence of Staphylococcus aureus, Pseudomonas aeruginosa, Salmonella choleraesuis, and Bacillus subtillis.

\section{DISCUSSION}

For the disinfectant concentration of $0.02 \%$, there is no statistically significant evidence that the percentage inhibition of the disinfectant against microorganisms (Staphylococcus aureus, Pseudomonas aeruginosa, and Salmonella choleraesuis), for the three exposure times $(5,10$, and $15 \mathrm{~min})$ is greater than $75 \%$ because of $P>0.05$. However, for the concentration of $0.04 \%$, there is statistically significant evidence that the percentage of inhibition of the disinfectant before microorganisms is higher than $75 \% . P<0.05$ at 15 min of exposure, except for Pseudomonas aeruginosa, presents a percentage of inhibition higher than $75 \%$ at 5 and $10 \mathrm{~min}$. For the concentrations of $0.08,1 \%$, and $2 \%$, the average inhibition was $100 \%$; therefore, the disinfectant was $100 \%$ at 5,10 , and 15 min of exposure. In the case of Bacillus subtillis, at $0.02 \%$ disinfectant concentration, there is no statistically significant evidence that the percentage inhibition of the disinfectant at the three exposure times $(3,6$, and $9 \mathrm{~h})$ is greater than $75 \%$ because $P>0.05$. However, for the concentration of $0.04 \%$, there is statistically significant evidence that the percentage of inhibition of the disinfectant against microorganisms is higher than $75 \%$ because $P<0.05$ for 6 and $9 \mathrm{~h}$ of exposure. For the concentrations of $0.08,1 \%$ and $2 \%$, the average was 100; therefore, the disinfectant is effective at that concentration in $100 \%$ at 3,6 , and $9 \mathrm{~h}$ of exposure. In all cases, the control showed the expected results with a $100 \%$ inhibition of microorganisms.

The tests carried out to determine the efficacy of the high-level hydrogen peroxide-based disinfectant of STERIS in the presence of Staphylococcus aureus are shown in table 1. The disinfectant concentration of $0.02 \%$, with an exposure time contact of 5,10 , and 15 min, demonstrated no bactericidal action above the minimum acceptance criterion established $75 \%$, for this microorganism.

At $0.04 \%$ disinfectant concentration, an increase in the percentage inhibition was observed, which does not meet the minimum acceptance criterion of $75 \%$ in an exposure time of $5 \mathrm{~min}$. However, when testing the concentration of $0.08 \%$, a $100 \%$ inhibition percentage was reached for the three established times. After 10 min of exposure at the $0.02 \%$ concentration, Staphylococcus aureus did not show an increase in the percentage of inhibition; comparatively, when testing the concentration of $0.04 \%$, an inhibition percentage of $43.75 \%$ was obtained, and, at a level of $0.08 \%$, total inhibition of growth was evidenced. After $15 \mathrm{~min}$ of contact with the disinfectant, an increase of $100 \%$ in the percentage of inhibition was observed with the concentration of $0.04 \%$, in the same way with a level of $0.08 \%$.

As shown in table 1 , the bacterial population is reduced in its totality, reaching a $100 \%$ inhibition percentage, after $5 \mathrm{~min}$ of treatment with the high-level hydrogen peroxide-based disinfectant of STERIS, when they were used in half the concentration (1\%) and the concentration recommended by the commercial house $(2 \%)$. These data show us that the partial or destruction of Staphylococcus aureus when put in contact with the disinfectant under study is determined by the concentration of the disinfectant and by the time of exposure. The reason why Staphylococcus aureus is not inhibited at concentrations of $0.02 \%$ and $0.04 \%$ with the high-level disinfectant of hydrogen peroxide-based STERIS is because this microorganism produces the extracellular enzyme catalase. This enzyme breaks down the hydrogen peroxide in water and molecular oxygen when this compound is in small amounts, according to [9] (Linley et al., 2012) in more significant quantities, under experimental conditions Staphylococcus aureus is inhibited by the accumulation of hydrogen peroxide in the medium.

Table 1 shows the results of the percentage of inhibition of the disinfectant evaluated against Pseudomonas aeruginosa. These results indicate that at $5 \mathrm{~min}$ with a concentration of $0.02 \%$, there was no inhibition of the microorganism. When the microorganisms were subjected to a concentration of $0.04 \%$, a decrease in the viability of the microorganism was observed as a function of the time of exposure to the disinfectant because a value of $88 \%$ was obtained after $5 \mathrm{~min}$, thereby complying with the minimum acceptance criterion of $75 \%$. The disinfectant is $100 \%$ effective when $0.08 \%, 1 \%$, and $2 \%$ concentrations were used. For a contact time with the disinfectant for $10 \mathrm{~min}$ at a concentration of $0.02 \%$, there was no evidence of inhibition, while, at the concentrations of $0.04 \%, 0.08 \%, 1 \%$, and $2 \%$, the percentage of inhibition was $100 \%$. At 15 min with a concentration of $0.02 \%$, there was a small amount of inhibition (table 1), whereas, with the concentrations of $0.04 \%$, $0.08 \%, 1 \%$, and $2 \%$, the inhibition was absolute.

These results show that, for this strain, the concentrations are recommended at $0.08 \%, 1 \%$, and $2 \%$ because they presented a significant percentage inhibition at 5,10 , and $15 \mathrm{~min}$ even in the shortest time, while a concentration of $0.02 \%$ and $0.04 \%$ is not recommended for use because the destruction of the microorganism is not guaranteed in any of the three exposure times. In table 1 , the total reduction of microbial growth is observed, when a concentration of $1 \%$ and the recommended concentration of $2 \%$ is used, for a contact time of $5 \mathrm{~min}$. These results indicate that the high-level disinfectant of STERIS, based on hydrogen peroxide, has a bactericidal effect for this microorganism using the recommended concentration. The results obtained indicate that Pseudomonas aeruginosa does not show resistance when it is subjected to a concentration of disinfectant based on $2 \%$ hydrogen peroxide, which complies with the guidelines established by the commercial house. According to the consulted bibliography, this microorganism is sensitive to hydrogen peroxide, an active component of the disinfectant under study because this generates a disturbance of the components of the cell membrane. A disturbance is also generated in chemiosmosis, which is the diffusion of ions across a permeable membrane, causing an alteration in the transport membrane and further causing damage to a cell wall $[6,10]$. Pseudomonas aeruginosa can present resistance by several mechanisms such as the variation in the composition of lipopolysaccharide (LPS) and the content of cations such as magnesium, which produces stable bonds between molecules of LPS and as a complement to this mechanism. This bacterium presents small porins that prevent the passage through the diffusion of certain antimicrobial substances [11]. Also, Pseudomonas aeruginosa can form glycocalyx, which is a polysaccharide or glycoprotein that covers the cell wall of this microorganism, thus forming a barrier against disinfectants $[6,12]$.

The results of the percentage inhibition of the high-level hydrogen peroxide-based disinfectant of STERIS against Salmonella choleraesuis is shown in table 1 , where the data demonstrates that at 
a concentration of $0.02 \%$, in contact time between 5 and $10 \mathrm{~min}$, the disinfectant has no inhibitory effect on this microorganism. Although a concentration of $0.04 \%$ shows an increase in the percentage of inhibition, it does not meet the minimum acceptance criterion of $75 \%$ for an interval between 5 and $10 \mathrm{~min}$ because an inhibition percentage between 0 and $63 \%$ was obtained. However, a total reduction of $100 \%$ was measured, when concentrations of $0.08 \%$ $1 \%$, and $2 \%$ were used. At $15 \mathrm{~min}$ of contact between the microorganism and the disinfectant, an increase in the percentage of inhibition of $42.15 \%$ was observed with a concentration of $0.02 \%$ (table 1 ). When using a concentration of $0.04 \%$ and a concentration of $0.08 \%$, a $100 \%$ inhibition percentage was obtained. Table 1 , shows the average of inhibition of the disinfectant against Salmonella choleraesuis, expressed as a percentage, in which it is observed that the bacterial population is reduced in its totality, reaching a level of $100 \%$ inhibition when a concentration of $1 \%$ is used, half of the recommendation and a concentration of $2 \%$ recommended by the commercial house with the minimum time of exposure. The low percentages of inhibition obtained when the levels of $0.02 \%$ and $0.04 \%$ were tested can be explained because this microorganism has several mechanisms that can elude the action of antimicrobial agents; for example, they can modify the cell membrane, making it less permeable to antimicrobials. They also have specific enzymes that modify or inactivate antimicrobials. Further, the resistance may be due to the action of a flow pump or modifications of the cell wall $[3,7,8,10]$.

Table 1 shows that, based on these results, we can say that, when a $0.02 \%$ disinfectant concentration is used for Bacillus subtilis microorganisms, a 50\% reduction in the population is achieved for a contact time between 3 and $6 \mathrm{~h}$, and a decrease of $87 \%$ for $9 \mathrm{~h}$. When analyzing the data using a concentration of $0.04 \%$, an increase in the inhibition percentage of $68 \%$ was achieved at $3 \mathrm{~h}, 96 \%$ at $6 \mathrm{~h}$, and $100 \%$ for $9 \mathrm{~h}$. The disinfectant is $100 \%$ effective when a concentration of $0.08 \%$ is used, for the three frames times established in the test. From the analysis of the results obtained (table 1) with half the concentration (1\%) and the recommended concentration (2\%), we can say that the high-level hydrogen peroxide-based disinfectant of STERIS has a high sporicidal power at $3 \mathrm{~h}$ of exposure because we achieved an absolute decrease of bacterial population for this microorganism. For this particular microorganism, different contact times with the disinfectant were established; in this case, it was 3,6 , and $9 \mathrm{~h}$ because this species has the capacity to form spores as resistance structures, and, by increasing the exposure time compared with the different concentrations, the disinfectant can exert its action against the spores, preventing the formation of the cortex between the internal and external membrane before the spore matures [6]. The resistance of Bacillus subtilis to disinfectants is attributed to the fact that the sporulated microorganisms form a barrier to the entry of antimicrobial agents because the membranes that surround the nucleus of the endospore act as an additional factor when limiting the penetration of the chemical agent [9]. When evaluating a disinfectant against a sporulated microorganism such as Bacillus subtilis, it is necessary to increase the exposure time for many reasons; for example, the spores have a core with a high content of calcium dipicolinate; in addition, the nucleus is partially dehydrated. This characteristic increases the thermoresistance of the spore, and at the same time, it confers resistance to chemical substances such as hydrogen peroxide. Also, from the low water content of the spore, the $\mathrm{pH}$ of the core cytoplasm contains high levels of specific core proteins termed "small acid-soluble spore proteins" (SASPs). These proteins bind tightly to the DNA in the spore's nucleus and protect it from potential damage from UV radiation, desiccation, and chemical agents $[3,8,12]$.

The results obtained in this study, for each microorganism, show that the inhibitory effect of the disinfectant is directly influenced by the exposure time; for this case, it is recommended to use the highlevel hydrogen peroxide-based disinfectant, STERIS, at a concentration of $2 \%$, with a contact time of $5 \mathrm{~min}$, as established by the producer. Several studies [10,13-15], in which the microorganisms Bacillus subtilis, Pseudomonas aeruginosa, and Staphylococcus aureus were used as a control, showed that hydrogen peroxide is $100 \%$ effective against these microorganisms at a concentration of $3 \%$ with a time of 5 min contact for vegetative bacteria and more than $2 \mathrm{~h}$ for the sporulated microorganism. The same effect was achieved in the present study, compared with all the strains tested, with the same time but at a lower concentration of the product at $2 \%$.

Refer to table 2 to examine the vegetative bacteria (Pseudomonas aeruginosa, Salmonella chole raesuis, and Staphylococcus aureus). The most significant reduction of microbial growth occurred in the strain of Pseudomonas aeruginosa, which reached a percentage of inhibition of $88 \%$ when subjected to a disinfectant concentration of $0.04 \%$ with an exposure time of $5 \mathrm{~min}$. These results are according to [13], which revealed that Pseudomonas aeruginosa could exhibit inhibition with different concentrations of this disinfectant. While the smallest reduction was observed with the strain of Staphylococcus aureus, in which, at $10 \mathrm{~min}$ of exposure, the population decreases to $44 \%$. On the other hand, the sporulated Bacillus subtilis strain showed a 69\% decrease in growth for the first $3 \mathrm{~h}$ of exposure to the disinfectant, at a concentration of $0.04 \%$. The reduction of the population on average was $100 \%$ for the levels of $0.08 \%, 1 \%$, and $2 \%$.

Based on the above, we can say that the high-level disinfectant of STERIS based on hydrogen peroxide is $100 \%$ effective when using the concentration recommended by the commercial house $(2 \%)$ in the shortest time of exposure. Likewise, we can establish that the minimum inhibitory concentration, i.e., the lowest level of the disinfectant capable of inhibiting in vitro the visible growth of microorganisms, was $0.08 \%$ because, with this value and in the shortest time of contact with the disinfectant evaluated, they achieved satisfactory results.

\section{CONCLUSION}

For the in vitro microbiological assays that tested the evaluation of three concentrations of the disinfectant, in this study satisfactory results were obtained. When facing the microbial strains against the high-level hydrogen peroxide-based disinfectant of STERIS at a $2 \%$ concentration, recommended by the commercial house, it was proved that it exerts a total inhibition of microbial growth in a time of exposure of $5 \mathrm{~min}$, proposed by the commercial house for cell vegetative and $6 \mathrm{~h}$ for the sporulated strain. It is worth mentioning that, in this study, the specific microorganisms were not used in the technical data sheet, i.e., the same ATCC, but studies carried out by [13], used Pseudomonas aeruginosa ATCC 9027 [13]; also used was Bacillus subtilis ATCC 6633, the same strains used for this study; further, $100 \%$ satisfactory results were reported for each microorganism when they used products with a concentration of hydrogen peroxide higher than $3 \%$.

\section{ACKNOWLEDGMENT}

We acknowledge the Environmental and Industrial Biotechnology Group at Microbiology Department in Pontificia Universidad Javeriana Bogota, Colombia.

\section{FINANCIAL SUPPORT AND SPONSORSHIP}

Pontificia Universidad Javeriana and REQPERA IPS SAS.

\section{AUTHOR CONTRIBUTIONS}

All authors contributed equally. All authors read and approved the final manuscript.

\section{CONFLICT OF INTERESTS}

\section{Declared none}

\section{REFERENCES}

1. Cadnum JL, Mana TSC, Jencson A, Thota P, Kundrapu S, Donskey CJ. The effectiveness of a hydrogen peroxide spray for decontamination of soft surfaces in hospitals. Am J Infect Control 2015;12:1357-9.

2. Kanchan C, Sangeeta D, Balasaheb G. A comparative survey of knowledge of antiseptic and disinfectant use and effect of the intervention on medical and surgical staff nurses in a tertiary care hospital. Asian J Pharm Clin Res 2018;11:120-3. 
3. Rios Castillo AG, Gonzalez Rivas F, Rodriguez Jerez JJ. Bactericidal efficacy of hydrogen peroxide-based disinfectants against gram-positive and gram-negative bacteria on stainless steel surfaces. J Food Sci 2017;82:2351-6.

4. Assoc Off. Anal Chem AOAC Official Methods of Analysis; 2000

5. Feridoz J, Roy A. Antibacterial activity of an aqueous alcoholic extract of Abutilon indicum aerial parts against $E$. faecalis-an in vitro study. Asian J Pharm Clin Res 2017;10:80-1.

6. Uchikawa M, Uchikawa K, Morais F, Quartim C, Queiroz R, Angelo C. Eficacia de la desinfección con alcohol al 70\% (p/v) de superficies contaminates sin limpieza previa. Rev Latino Am Enferm 2013;21:1-6.

7. Kohli R, Mittal KL. Developments in surface contamination and cleaning; 2013.

8. Perumal PK, Wand ME, Sutton JM, Bock LJ. Evaluation of the effectiveness of hydrogen-peroxide-based disinfectants on biofilms formed by gram-negative pathogens. J Hosp Infect 2014;87:227-33.

9. Linley E, Denyer SP, McDonnell G, Simons C, Maillard JY. Use of hydrogen peroxide as a biocide: new consideration of its mechanisms of biocidal action. J Antimicrobial Chemother 2012;67:1589-96.
10. Kanemitsu K. A comparative study of ethylene oxide gas, hydrogen peroxide gas plasma, and low-temperature steam formaldehyde sterilization. Infect Control Hosp Epidemiol 2005;26:486-9.

11. Lemmen S, Scheithauer S, Häfner H, Yezli S, Mohr M, Otter JA. Evaluation of hydrogen peroxide vapor for the inactivation of nosocomial pathogens on porous and nonporous surfaces. Am J Infect Control 2015;43:82-5.

12. Horn K, Otter JA. Hydrogen peroxide vapor room disinfection and hand hygiene improvements reduce clostridium difficile infection, methicillin-resistant Staphylococcus aureus, vancomycin-resistant enterococci, and extended-spectrum $\beta$ lactamase. Am J Infect Control 2015;43:1354-6.

13. Setlow B, Yu J, Li YQ, Setlow P. Analysis of the germination kinetics of individual Bacillus subtilis spores treated with hydrogen peroxide or sodium hypochlorite. Lett Appl Microbiol 2013;57:259-65.

14. Gellatly SL, Hancock REW. Pseudomonas aeruginosa: New insights into pathogenesis and host defenses. Pathog Dis 2013;67:159-73

15. Arnaouteli S, MacPhee CE, Stanley-wall NR. Just in case it rains: building a hydrophobic biofilm the Bacillus subtilis way. Curr Opinion Microbiol 2016;34:7-12. 